Check for updates

Cite this: RSC Adv., 2017, 7, 52105

Received 16th July 2017

Accepted 25th October 2017

DOI: 10.1039/c7ra07815c

rsc.li/rsc-advances

\section{Theoretical calculation and experiment study on the electronic structure, microstructures and photocatalytic activity of $\mathrm{N}-\mathrm{Al}$ codoped $\mathrm{TiO}_{2} \uparrow$}

\begin{abstract}
Dandan Wang, Yongjie Zheng, (DD * Jingzhi Tian, Tao Jing, * Wei Kan and Yi Hu
To more accurately demonstrate how the electronic structure was changed by codoping $\mathrm{TiO}_{2}$ with $\mathrm{N}-\mathrm{Al}$ and to explain the origin of the enhanced photocatalytic activity by $\mathrm{N}-\mathrm{Al}$-codoped $\mathrm{TiO}_{2}$, we investigated the electronic structures and microstructures of $\mathrm{N}$ monodoped, $\mathrm{Al}$ monodoped, and $\mathrm{N}-\mathrm{Al}$ codoped anatase $\mathrm{TiO}_{2}$ by theoretical calculation and experiments. It was found that $\mathrm{N}$ monodoping and $\mathrm{Al}$ monodoping could effectively narrow the band gap. The effect was doubled when $\mathrm{TiO}_{2}$ was codoped with $\mathrm{N}$ and Al because the emergence of the $N 2 p$ state made the VBM move to a higher energy level and the emergence of the Al $3 p$ state made the CBM move to a lower energy level in the system. Moreover, codoping of $\mathrm{N}$ and $\mathrm{Al}$ into $\mathrm{TiO}_{2}$ did not change the microstructures of $\mathrm{TiO}_{2}$ catalysts although it was proven that both $\mathrm{N}$ and $\mathrm{Al}$ atoms were codoped into $\mathrm{TiO}_{2} . \mathrm{N}$ and $\mathrm{Al}$-codoped $\mathrm{TiO}_{2}$ displayed a higher crystallinity and a higher specific surface area than others. According to the results about the degradation rate and the dynamics of the catalysts, $\mathrm{N}-\mathrm{Al}-\mathrm{TiO}_{2}$ exhibited the best photocatalytic activity; this suggested that $\mathrm{N}$ and $\mathrm{Al}$ were combined to enhance the photocatalytic activity of $\mathrm{TiO}_{2}$.
\end{abstract}

\section{Introduction}

$\mathrm{TiO}_{2}$ is a photocatalyst that can be used for decomposing pollutants with benefits of low-cost, non-toxic, high chemical stability, and high oxidative power. ${ }^{1,2}$ However, $\mathrm{TiO}_{2}$ can only show high photocatalytic activity under ultraviolet light; ${ }^{3}$ this leads to a poor utilization of solar energy. Therefore, the commercialization of $\mathrm{TiO}_{2}$ is limited greatly. ${ }^{4}$ Several methods, including substitutions with transition, precious, and rare earth metals, have been used to overcome the drawbacks. ${ }^{5,6}$ However, these methods are still not as good as expected because either the costs of the metals are high or their resources are scarce. Thus, it is necessary to seek some cheaper and accessible metal elements to be doped into $\mathrm{TiO}_{2}$ to improve the photocatalytic activity under visible light., ${ }^{7,8}$

In recent years, it has been proven that the optical absorption of $\mathrm{TiO}_{2}$ can be increased using a dopant, including a nonmetal and metal. Meng et al. ${ }^{9}$ pointed out that $\mathrm{TiO}_{2}$ codoped with $\mathrm{N}$ and a transition metal could display photocatalytic activity under visible light. Additionally, they explored the correlation between the electronic structure and the optical properties using the density functional theory (DFT).

Several studies indicated that the photocatalytic activity was increased under visible light by doping $\mathrm{TiO}_{2}$ with some metal

College of Chemistry and Chemical Engineering, Qiqihar University, Qiqihar, Heilongjiang, 161006, China. E-mail: zyj1964@163.com; jtkr@163.com

$\dagger$ Electronic supplementary information (ESI) available: Addition SEM of $\mathrm{N}-\mathrm{TiO}_{2}$ and $\mathrm{Al}-\mathrm{TiO}_{2}$, and XPS survey spectrum of catalytics. See DOI: 10.1039/c7ra07815c atoms such as Fe, Er, and Al. Especially, Al atom can substitute Ti atom because their ionic radii are similar. Additionally, many studies have shown that the spectra of $\mathrm{TiO}_{2}$ doped with an appropriate amount of $\mathrm{Al}$ could exhibit a red-shift in the UVvisible absorption bands, ${ }^{10,11}$ and $\mathrm{Al}^{-\mathrm{TiO}_{2}}$ displayed a good UV absorption capability. Moreover, the photocatalytic activity of $\mathrm{Al}-\mathrm{TiO}_{2}$ was higher than that of pure $\mathrm{TiO}_{2} \cdot{ }^{10}$ Liu et al. ${ }^{12}$ prepared an Al-doped $\mathrm{TiO}_{2}$ thin film by a hydrothermal method; after doping, the photovoltaic efficiency of $\mathrm{TiO}_{2}$ increased up to $6.48 \%$, which was $1.1 \%$ higher as compared to that of the pure $\mathrm{TiO}_{2}$ thin film.

Besides metal doping, the nonmetal and metal codoping have also been investigated extensively. Some studies indicate that $\mathrm{N}$ codoping with some metals can considerately change the band gap of $\mathrm{TiO}_{2},{ }^{13-15}$ thus, its photocatalytic activity is improved significantly under visible light. In particular, the codoped anatase $\mathrm{TiO}_{2}$ plays a pivotal role in the light absorption process. Therefore, it is important to investigate how $\mathrm{N}-\mathrm{Al}$ codoping $\mathrm{TiO}_{2}$ affects the photocatalytic activity.

Generalized gradient approximation (GGA) or local density approximation (LDA) is the routine method used for studying the electronic properties of the doped anatase titania based on the DFT and have achieved great success in many compounds. However, they failed while dealing with some systems associated with a strong cross-linking relationship between inner molecules (such as transition metal oxides). Moreover, the value of the band gap obtained by the theoretical calculations is much lower than the experimental value. ${ }^{16}$ The reason is that the system should be insulated, but actually, it is not. ${ }^{17,18}$ Therefore, 
it is necessary to figure out how to reduce the difference and make the study of the electronic structures of the doped $\mathrm{TiO}_{2}$ more accurate. The Hubbard model is an effective correction method for $\mathrm{GGA}^{19}$ and has been applied successfully in the strongly correlated systems. However, the model is still not accurate enough to predict the band gap of transition metal oxides, such as $\mathrm{TiO}_{2}$, because of the natural errors generated from the self-interaction. Liu et $a .^{20}$ calculated the band gap of anatase $\mathrm{TiO}_{2}$ using this method, and the value they obtained was about $2.12 \mathrm{eV}$. However, the experimental value was $3.22 \mathrm{eV}$. It is clear that the value calculated based on GGA is much smaller than that obtained from experiments.

To improve the photocatalytic activity of $\mathrm{TiO}_{2}$ under visible light, in this study, electronic structures were calculated systematically by the GGA $+\mathrm{U}$ method for $\mathrm{N}-\mathrm{Al}$ codoped $\mathrm{TiO}_{2}$, and then, several computational models were constructed to explain the changes in the electronic structures by comparing pure $\mathrm{TiO}_{2}$ with the doped $\mathrm{TiO}_{2}$. We also synthesized anatase $\mathrm{TiO}_{2}, \mathrm{~N}-\mathrm{TiO}_{2}, \mathrm{Al}-\mathrm{TiO}_{2}$, and N-Al- $-\mathrm{TiO}_{2}$ by a sol-gel method and further explored the root causes for the enhancement of the photocatalytic activity under visible light.

\section{Computational details and method}

\subsection{Materials}

Tetrabutyl titanate, aluminum sulfate, ethyl alcohol, glacial acetic acid, dilute nitric acid, urea, and methyl orange (MO) were obtained from Tianjin Commie Chemical Reagent Co. Ltd. Water used herein was secondary deionized water.

\subsection{Establishment of the doping system model}

Ultrasoft pseudopotentials of the first-principle calculation were applied in this research. On the basis of the GGA, PBE parameterization was used to show the interdependency potentials and the exchange. A relaxed $2 \times 2 \times 1$ anatase supercell was constructed from the doped systems, which contained 16 titanium and 32 oxygen atoms. The supercell was very successful in the investigation of $\mathrm{TiO}_{2}$ doped with various elements. $^{21,22}$

In the $\mathrm{N}-\mathrm{Al}$ codoped $\mathrm{TiO}_{2}$ model, we compared two configurations (see Fig. 1): (1) a $\mathrm{N}$ replaced $\mathrm{O}$ at the $\mathrm{O}$ site and an $\mathrm{Al}$ substituted the neighbor Ti at the Ti site (see Fig. 1(a)) and (2) similarly, a $\mathrm{N}$ replaced $\mathrm{O}$ at the $\mathrm{O}$ site and an $\mathrm{Al}$ substituted $\mathrm{Ti}$ at the Ti site; however, $\mathrm{N}$ and $\mathrm{Al}$ were far away from each other (see Fig. 1(b)). According to the total energy obtained from the geometry optimization, it was concluded that the first configuration was more stable than the second configuration. Therefore, we chose the former as the model. In this study, the configurations of the valence electron of various atoms were involved, which were $\mathrm{O}\left(2 \mathrm{~s}^{2} 2 \mathrm{p}^{4}\right), \mathrm{Ti}\left(3 \mathrm{~d}^{2} 4 \mathrm{~s}^{2}\right), \mathrm{N}\left(2 \mathrm{~s}^{2} 2 \mathrm{p}^{3}\right)$, and Al $\left(3 \mathrm{~s}^{2} 3 \mathrm{p}^{1}\right)$. By setting the cut-off energy at $380 \mathrm{eV}$, the wave functions of the valence electron were expanded by a series of plane wave pseudopotentials. The geometry optimization and the calculation of the electronic structures were achieved via the Monkhorst-Pack scheme with a $3 \times 3 \times 3 \mathrm{~K}$-point grid
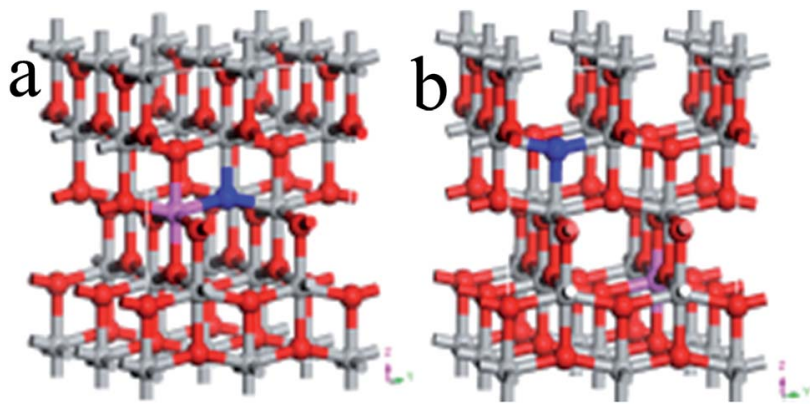

Fig. 1 Perspective view of the $2 \times 2 \times 1$ supercell of $\mathrm{N}-\mathrm{Al}$ codoped anatase $\mathrm{TiO}_{2}$, in which $\mathrm{N}$ and $\mathrm{Al}$ are next to each other (a) and far away (b). The red, gray, pink, and blue spheres represent $\mathrm{O}, \mathrm{Ti}, \mathrm{Al}$, and $\mathrm{N}$ atoms, respectively.

sampling. When the residual force of the whole atoms was lower than $0.01 \mathrm{eV}^{-1}$, all the atoms were absolutely loosed.

\subsection{Synthesis of $\mathrm{N}-\mathrm{Al}$ codoped $\mathrm{TiO}_{2}$}

The N-Al codoped $\mathrm{TiO}_{2}$ was prepared using the sol-gel method. ${ }^{23-25}$ The solution A was prepared by adding tetrabutyl titanate $(10.0 \mathrm{~mL})$ to absolute ethanol $(40.0 \mathrm{~mL})$ dropwise under stirring. The solution $\mathrm{B}$ was prepared by dissolving various amounts of urea and aluminum sulfate octadecahydrate in a solution of water $(10.0 \mathrm{~mL})$, absolute ethanol $(30.0 \mathrm{~mL})$, and glacial acetic acid $(4.0 \mathrm{~mL})$ at $\mathrm{pH}$ 3.0. The solution B was added drop by drop to the solution A under stirring until the mixed solution formed the sol, and then, it was moved to the reaction kettle to form the gel for $48 \mathrm{~h}$. The $\mathrm{N}-\mathrm{Al}$ codoped $\mathrm{TiO}_{2}$ catalyst was fabricated by filteration, drying, and calcination.

\subsection{Photocatalytic activity evaluation}

The photocatalytic experiments were carried out using a photocatalytic reaction apparatus with a xenon lamp as a simulated daylight source. The photocatalytic activity of the catalyst was evaluated by the degradation rate of the photocatalytic degradation of methyl orange. Briefly, the catalyst $(0.1 \mathrm{~g})$ and $50 \mathrm{~mL}$ of the methyl orange (MO) solution were mixed, sonicated for $10 \mathrm{~min}$, placed in the photocatalytic reaction instrument, and stirred for $30 \mathrm{~min}$ to reach the adsorption equilibrium (avoiding light). Then, the samples were obtained every $30 \mathrm{~min}$ and centrifuged, and the absorbance was measured. According to the LambertBeer law, the degradation rate of MO was calculated as follows:

$$
\eta=\left(A_{0}-A_{t}\right) / A_{0} \times 100 \%
$$

where $\eta$ is the degradation rate of $\mathrm{MO}, A_{0}$ is the initial absorbance of the non-degraded MO solution, and $A_{t}$ is the absorbance of the MO solution after illumination for $t$ min.

\subsection{Characterizations}

The morphology of the catalysts was observed by scanning electron microscopy (SEM) and transmission electron microscopy (TEM). The crystals of the catalysts were determined by Xray diffraction (XRD). The elementary compositions were analyzed by X-ray photoelectron spectroscopy (XPS). The band 
gaps of the catalysts were calculated based on the UV-vis diffuse reflectance spectra (UV-vis DRS). The specific surface areas were measured by $\mathrm{N}_{2}$ adsorption-desorption isotherms.

\section{Results and discussion}

\subsection{Determination of Hubbard parameter $\left(U_{\text {eff }}\right)$}

The GGA + U method was applied to depict the optimal band gap produced by the $\mathrm{d}$ and $\mathrm{f}$ electron systems and the interaction between the intra-atomic electrons. Moreover, the Hubbard parameter $\left(U_{\text {eff }}\right)$ was appropriately determined by the GGA + U calculations. ${ }^{26}$

As shown in Table 1, the band gap was narrowed along with a decrease of Hubbard $\left(U_{\text {eff }}\right)$ for pure $\mathrm{TiO}_{2}$. By this approach, the optimum $U_{\text {eff }}$ of $\mathrm{Ti} 3 \mathrm{~d}$ was calculated for pure $\mathrm{TiO}_{2}$, and it was $8.30 \mathrm{eV}$. Based on $U_{\text {eff }}$, the band gap of $3.204 \mathrm{eV}$ was obtained, which was consistent with the experimental value $(3.2 \mathrm{eV}) .{ }^{27}$

\subsection{Electronic structures}

After the optimum $U_{\text {eff }}$ was determined, the band structures were calculated for pure anatase $\mathrm{TiO}_{2}, \mathrm{TiO}_{2}$ doped with $\mathrm{N}, \mathrm{TiO}_{2}$ doped with $\mathrm{Al}$, and anatase $\mathrm{TiO}_{2}$ codoped with $\mathrm{N}-\mathrm{Al}$, and the results are shown in Fig. 2.

According to the previous study, the lattice parameters obtained by the experiments were $a=b=3.782 \AA$, and $c=9.502 \AA$ for anatase $\mathrm{TiO}_{2} \cdot{ }^{29-32}$ Based on the method used herein, the values calculated by the supercell $(2 \times 2 \times 1)$ were $a=b=3.791$, and $c=$ $9.750 \AA$. As expected, the theoretical values are very close to the practical values; this proved that the supercell we designed was successful for experiments. As shown in Fig. 2(a), the band structures were calculated for pure anatase $\mathrm{TiO}_{2}$, where the minimum value of the conduction band (CBM) and the maximum value of the valence band (VBM) were the gamma $(G)$ point and $M$ $\rightarrow G$ region, respectively. These results imply that pure anatase $\mathrm{TiO}_{2}$ is an indirect band gap semiconductor. It also means that as compared to the standard GGA or LDA methods, the GGA + U method can provide a more accurate prediction on the band gap.

Moreover, to obtain the origins of the electronic structures of $\mathrm{TiO}_{2}$ doped with different elements, we calculated the partial density of the states (PDOS) and the total density of the states (TDOS) for anatase $\mathrm{TiO}_{2}$, and the results are shown in Fig. 3(a) and (b). Moreover, we analyzed their electronic characteristics through the calculations with anatase $\mathrm{TiO}_{2}$. As shown in Fig. 3, based on the valence band (VB), the state of $\mathrm{O} 2 \mathrm{p}$ of pure $\mathrm{TiO}_{2}$ would be dominant, and it was hybridized with the orbit of $\mathrm{Ti}$ $3 \mathrm{~d}$. On the other hand, according to the conduction band (CB), the state of $\mathrm{Ti} 3 \mathrm{~d}$ would be dominant. These results are consistent with the previous studies. ${ }^{33-35}$ The electronic structure of $\mathrm{TiO}_{2}$ doped with $\mathrm{N}$ is shown in Fig. 2(b), where the $\mathrm{O}$ atom is replaced by a $\mathrm{N}$ atom. The VBM increased to $0.0679 \mathrm{eV}$,

Table 1 Hubbard parameter $\left(U_{\text {eff }}\right)$ and the corresponding band gap $\left(E_{\mathrm{g}}\right)$ for pure anatase $\mathrm{TiO}_{2}$

\begin{tabular}{llllllll}
\hline$U_{\text {eff }} / \mathrm{eV}$ & 8.50 & 8.47 (ref. 28) & 8.40 & 8.35 & 8.30 & 8.25 & 0 \\
$E_{\mathrm{g}} \mathrm{eV}$ & 3.256 & 3.249 & 3.230 & 3.217 & 3.204 & 3.190 & 2.1
\end{tabular}

and the CBM remained almost unchanged. The band gap was narrowed to $3.1361 \mathrm{eV}$ for the $\mathrm{N}$ monodoped $\mathrm{TiO}_{2}$. The doping led to the formation of impurity bands in the forbidden gap nearby the Fermi level. As shown in Fig. 3, the upward shift of the VBM was caused by the emergence of the $\mathrm{N} 2 \mathrm{p}$ state as compared to that of the pure $\mathrm{TiO}_{2}$; this explained how the band gap could become narrower. Combining all results together (Fig. 3 and 2), we proposed that the VBM and the CBM were dominant due to the Ti $3 \mathrm{~d}$ state in $\mathrm{N}$ doped $\mathrm{TiO}_{2}{ }^{36}$ As shown in Fig. 2(c), the VBM in Al-doped $\mathrm{TiO}_{2}$ remained unchanged, but the CBM had a decrease of $0.2589 \mathrm{eV}$ as compared to that of pure $\mathrm{TiO}_{2}$. Thus, the calculated band gap was $2.945 \mathrm{eV}$. After the substitution of Ti with $\mathrm{Al}$ atom (Fig. 3), a part of the $\mathrm{Al} 3 \mathrm{~s}$ and $\mathrm{Al} 3 \mathrm{p}$ states appeared above the Fermi level, which constructed as the CBM of the system. The downward shift of the bottom conduction band was caused by the emergence of the $\mathrm{Al} \mathrm{3s}$ and $\mathrm{Al} 3 \mathrm{p}$ states, which led to the band gap narrowing. ${ }^{37}$ For N-Al codoped anatase $\mathrm{TiO}_{2}$, the result of the calculation for the electronic structure is displayed in Fig. 2(d). It was found that the CBM of the codoped system decreased by $0.3277 \mathrm{eV}$ as compared to that of pure $\mathrm{TiO}_{2}$. In contrast, the VBM was only decreased by $0.03171 \mathrm{eV}$. Noticeably, the band gap of N$\mathrm{Al}$ codoped $\mathrm{TiO}_{2}$ was determined by both the VBM and the CBM, and the final value for the band gap was $2.908 \mathrm{eV}$, which was $0.296 \mathrm{eV}$ lower than that obtained in pure anatase $\mathrm{TiO}_{2}$. This indicates that the band gap was much narrower than that induced by $\mathrm{Al}$ monodoping or $\mathrm{N}$ monodoping, or the pure $\mathrm{TiO}_{2}$.

Additionally, it was found that some of the $\mathrm{N} 2 \mathrm{p}$ states appeared above the Fermi level and became a component of the CBM, as shown in Fig. 3. Because of the combined effects of the $\mathrm{N} 2 \mathrm{p}, \mathrm{Al} 3 \mathrm{~s}$, and $\mathrm{Al} 3 \mathrm{p}$ states, a more obvious downward shift of the bottom conduction band was observed and resulted in the narrower band gap.

\subsection{The microstructure and composition of the catalysts}

SEM, TEM, and XRD were used to determine the microstructures of the catalysts. The morphologies of pure $\mathrm{TiO}_{2}$ and N-Al-
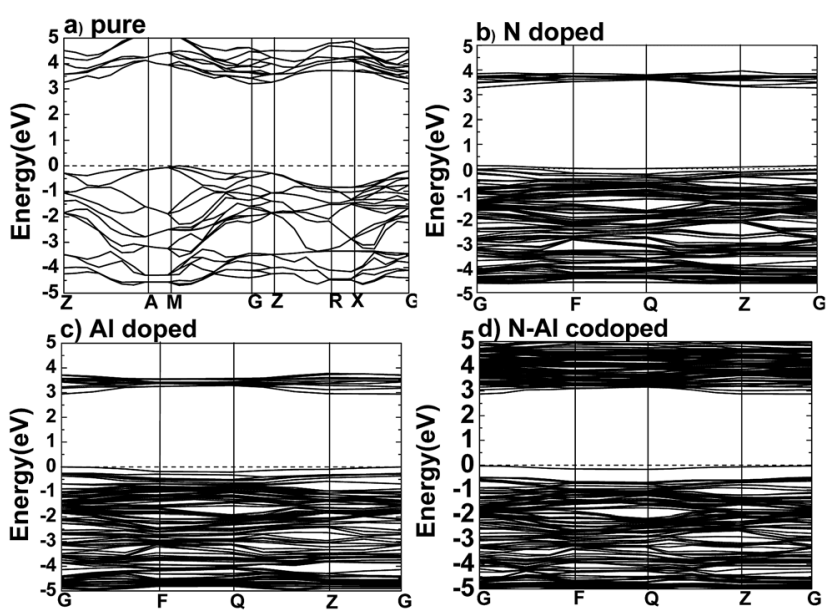

Fig. 2 The band structures for (a) pure $\mathrm{TiO}_{2}$, (b) $\mathrm{N}$ monodoped, (c) Al monodoped, and (d) $\mathrm{N}-\mathrm{Al}$ codoped anatase $\mathrm{TiO}_{2}$ calculated by the $\mathrm{GGA}+U$ method along the high symmetry lines of Brillouin zone. The dashed lines represent the Fermi level $E_{\mathrm{f}}$. 

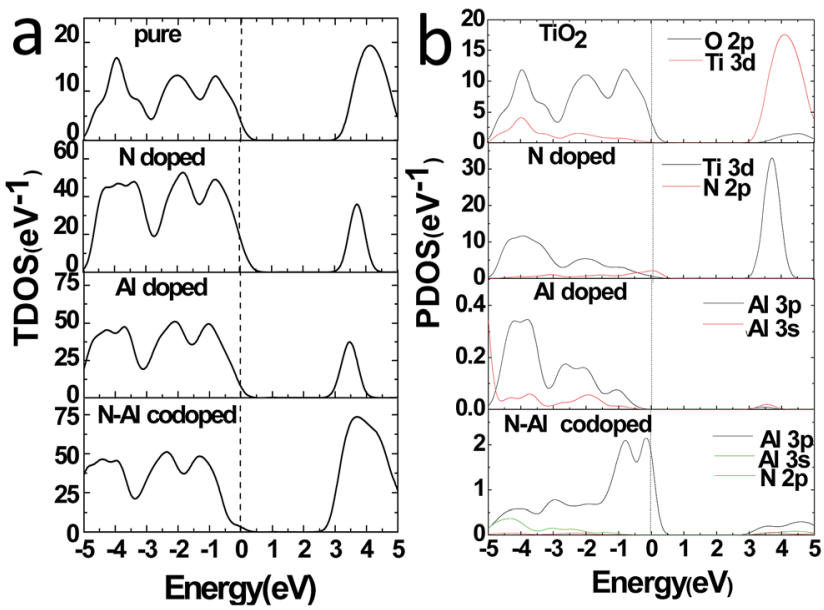

Fig. 3 TDOS (a) and PDOS (b) were calculated by the GGA + U method and plotted for pure $\mathrm{TiO}_{2}, \mathrm{~N}$ monodoped, Al monodoped, and $\mathrm{N}-\mathrm{Al}$ codoped anatase $\mathrm{TiO}_{2}$. The Fermi level of these systems is displayed with a gray dashed line.

$\mathrm{TiO}_{2}$ are shown in Fig. 4(a) and (b), respectively. It was clear that the particles were uniform and well-dispersed. Upon comparing Fig. 4(a) with Fig. 4(b), it can be seen that the morphology of the catalyst codoped with $\mathrm{N}$ and $\mathrm{Al}$ elements is not changed significantly. The TEM images of pure $\mathrm{TiO}_{2}$ and $\mathrm{N}-\mathrm{Al}-\mathrm{TiO}_{2}$ (Fig. 4(c) and (d)) further confirmed the morphologies, which were consistent with those revealed by SEM. The phase structures of pure $\mathrm{TiO}_{2}, \mathrm{~N}-\mathrm{TiO}_{2}, \mathrm{Al}-\mathrm{TiO}_{2}$, and $\mathrm{N}-\mathrm{Al}-\mathrm{TiO}{ }_{2}$ were studied by XRD, and the results are shown in Fig. 4(e) and (f). The $2 \theta$ peaks of pure $\mathrm{TiO}_{2}$ were at $25.3^{\circ}, 38.1^{\circ}, 48.42^{\circ}, 54.22^{\circ}$, and $63.08^{\circ}$. Thus, according to the JCPDS card, no. 73-1764, the crystal form of $\mathrm{TiO}_{2}$ was mainly the anatase type. Similarly, after pure $\mathrm{TiO}_{2}$ was doped, the crystal forms did not show any significant changes. This was consistent with the crystal form of the catalysts achieved from the theoretical calculation. The (101) diffraction peak was used as a reference, and the crystallinities and crystal plane distance of $(101)^{38,39}$ were calculated, as shown in Table 2. Compared to pure $\mathrm{TiO}_{2}, \mathrm{~N}-\mathrm{Al}-\mathrm{TiO}_{2}$ displayed a higher crystallinity, which could be a beneficial to improve the photocatalytic activity of the catalyst. According to the Fig. 4(e) and Table 2, the crystal plane distances of (101) for pure $\mathrm{TiO}_{2}$, $\mathrm{N}-\mathrm{TiO}_{2}, \mathrm{Al}-\mathrm{TiO}_{2}$, and $\mathrm{N}-\mathrm{Al}-\mathrm{TiO}_{2}$ were different; this indicated that $\mathrm{N}$ and $\mathrm{Al}$ atoms were doped into the pure $\mathrm{TiO}_{2}$ lattice.

The chemical composition of the $\mathrm{N}-\mathrm{Al}-\mathrm{TiO}_{2}$ catalyst was investigated by XPS. Fig. 4(g) shows the XPS survey spectrum of $\mathrm{N}-\mathrm{Al}-\mathrm{TiO}_{2}$, in which the binding energy peaks of $\mathrm{O} 1 \mathrm{~s}, \mathrm{Ti} 2 \mathrm{p}, \mathrm{N}$ 1s, and $\mathrm{Al} 2 \mathrm{p}$ are located at $530.08 \mathrm{eV}, 458.31 \mathrm{eV}, 399.73 \mathrm{eV}$, and $73.9 \mathrm{eV}$, respectively. According to Fig. 4(h), the peak at $399.33 \mathrm{eV}$ could be ascribed to the binding energy of $\mathrm{N} 1 \mathrm{~s}$ in $\mathrm{N}-$ $\mathrm{TiO}_{2}$. The peak position of $\mathrm{N} 1 \mathrm{~s}$ in $\mathrm{N}-\mathrm{TiO}_{2}$ was the same as the position of $\mathrm{N} 1 \mathrm{~s}$ in $\mathrm{N}-\mathrm{Al}-\mathrm{TiO}_{2}$, but with largely different intensities. The intensity of the peak of the $\mathrm{N}-\mathrm{Al}-\mathrm{TiO}_{2}$ catalyst nearly doubled that of the peak of $\mathrm{N}-\mathrm{TiO}_{2}$; this might be attributed to $\mathrm{Al}$ doped in $\mathrm{TiO}_{2}$. In Fig. 4(i), the binding energies of $\mathrm{Ti} 2 \mathrm{p}_{3 / 2}$ and $\mathrm{Ti} 2 \mathrm{p}_{1 / 2}$ of pure $\mathrm{TiO}_{2}$ were observed at $458.1 \mathrm{eV}$ and $463.7 \mathrm{eV}$, respectively, which indicated that the $\mathrm{Ti}^{4+}$ species existed in the
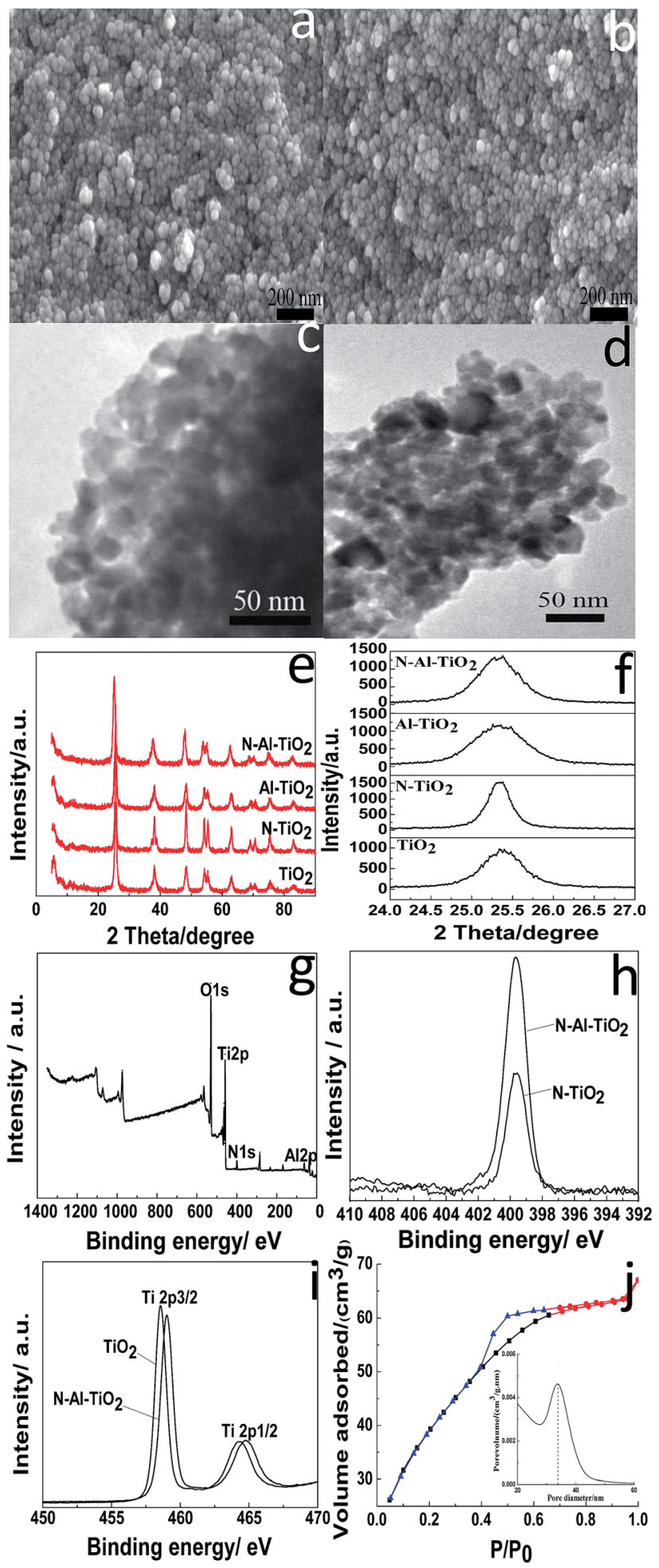

Fig. $4 \mathrm{SEM}$ images of $\mathrm{TiO}_{2}(\mathrm{a})$ and $\mathrm{N}-\mathrm{Al}-\mathrm{TiO}_{2}$ (b), $\mathrm{TEM}$ images of $\mathrm{TiO}_{2}$ (c) and $\mathrm{N}-\mathrm{Al}-\mathrm{TiO}_{2}$ (d), (e) XRD patterns of pure $\mathrm{TiO}_{2}, \mathrm{~N}-\mathrm{TiO}_{2}, \mathrm{Al}-\mathrm{TiO}_{2}$, and $\mathrm{N}-\mathrm{Al}-\mathrm{TiO}_{2}$, (f) the (101) diffraction peaks of pure $\mathrm{TiO}_{2}, \mathrm{~N}-\mathrm{TiO}_{2}$, $\mathrm{Al}-\mathrm{TiO}_{2}$, and $\mathrm{N}-\mathrm{Al}-\mathrm{TiO}_{2}$, (g) XPS survey spectrum of $\mathrm{N}-\mathrm{Al}-\mathrm{TiO}_{2}$, (h) the peaks of $\mathrm{N} 1 \mathrm{~s}$ from $\mathrm{N}-\mathrm{TiO}_{2}$ and $\mathrm{N}-\mathrm{Al}-\mathrm{TiO}_{2}$, (i) the peaks of $\mathrm{Ti} 2 \mathrm{p}_{3 / 2}$ and $2 \mathrm{p}_{1 / 2}$ from $\mathrm{TiO}_{2}$ and $\mathrm{N}-\mathrm{Al}-\mathrm{TiO}_{2}$, and (j) $\mathrm{N}_{2}$ adsorption-desorption curves of $\mathrm{N}-\mathrm{Al}-\mathrm{TiO}_{2}$. 
Table 2 The structural information for the samples

\begin{tabular}{|c|c|c|c|}
\hline Samples & $\mathrm{TiO}_{2}$ & $\mathrm{Al}-\mathrm{TiO}_{2}$ & $\mathrm{~N}-\mathrm{Al}-\mathrm{TiO}_{2}$ \\
\hline Peaks of (101) (degree) & 25.34 & 25.30 & 25.31 \\
\hline Crystal plane distance of (101) (nm) & 0.35122 & 0.35174 & 0.35161 \\
\hline Crystallinity $^{a}$ & 1.00 & 1.57 & 1.68 \\
\hline Theoretical band gap (eV) & 3.204 & 2.945 & 2.908 \\
\hline Experimental band gap (eV) & 3.105 & 2.786 & 2.713 \\
\hline Specific surface area $\left(\mathrm{m}^{2} \mathrm{~g}^{-1}\right)$ & 59.22 & 95.76 & 127.5 \\
\hline Pore volume $\left(\mathrm{cm}^{3} \mathrm{~g}^{-1}\right)$ & 0.0893 & 0.1259 & 0.1603 \\
\hline Average pore diameter (nm) & 60.30 & 52.61 & 50.26 \\
\hline The first-order rate $\left(\mathrm{min}^{-1}\right)$ & 0.00061 & 0.00132 & 0.00447 \\
\hline
\end{tabular}

${ }^{a}$ The crystallinity of anatase $\mathrm{TiO}_{2}$ was calculated using the (101) peak of anatase $\mathrm{TiO}_{2}$ as a reference.

form of $\mathrm{TiO}_{2}$. In addition, compared to that of pure $\mathrm{TiO}_{2}$, the binding energy of $\mathrm{Ti} 2 \mathrm{p}$ in $\mathrm{N}-\mathrm{Al}-\mathrm{TiO}_{2}$ shifted to the right because $\mathrm{N}$ and $\mathrm{Al}$ were codoped to form the impurity energy levels; this facilitated the transition of electrons and resulted in a lower density of the Ti electron cloud and increase of binding energy. These results are consistent with the theoretical calculations (Fig. 2 and 3).

\section{4 $\mathrm{N}_{2}$ adsorption-desorption and UV-vis diffuse reflectance spectra}

The surface physicochemical property of the $\mathrm{N}-\mathrm{Al}-\mathrm{TiO}_{2}$ catalyst was characterized by $\mathrm{N}_{2}$ adsorption-desorption isotherms, as shown in Fig. 4(j). Based on the IUPAC rules, the $\mathrm{N}-\mathrm{Al}-\mathrm{TiO}_{2}$ catalyst displayed type IV pattern curve, which implied the existence of the mesoporous structure. The results from BET analysis are shown in Table 2. It was obvious that the specific surface area of $\mathrm{N}-\mathrm{Al}-\mathrm{TiO}_{2}$ was higher than that of the others, which increased the contact area with the reactants. Thus, it is beneficial for the improvement of the photocatalytic activity of the composite material.

To study the changes in the band gap caused by the doping elements, the analysis with a UV-vis diffuse reflectance spectra was carried out, and the results are shown in Fig. 5(a) and (b). Compared to pure $\mathrm{TiO}_{2}, \mathrm{~N}$ monodoped and $\mathrm{Al}$ monodoped $\mathrm{TiO}_{2}$ showed a blue-shift; however, the $\mathrm{N}-\mathrm{Al}$ codoped $\mathrm{TiO}_{2}$ showed a slight red-shift. To further study the nature of the transition and the band gap of the composite materials, the following equation $^{40}$ was used: $(a h v)^{n}=K\left(h v-E_{\mathrm{g}}\right)$, where $a$ is the
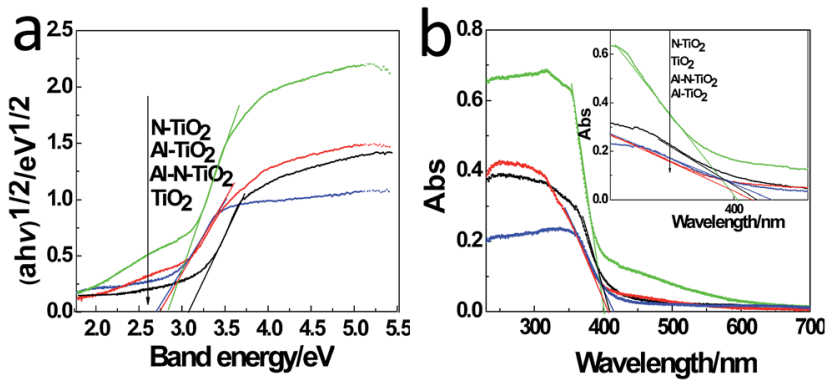

Fig. 5 (a) UV-vis diffuse reflectance spectra and (b) plots of $(a h v)^{1 / 2}$ versus energy $(h v)$ of the samples.

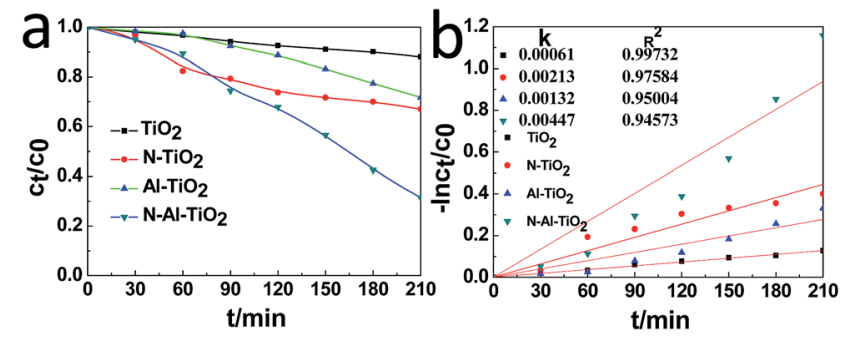

Fig. 6 (a) Photocatalytic degradation of $\mathrm{MO}$ by different catalysts and (b) the kinetics of the photocatalytic degradation of MO by them under the simulated visible light irradiation.

absorption coefficient, $h v$ is the absorption energy, $n$ is $1 / 2$ for a direct transition, $K$ is the parameter that is related to the effective masses associated with the valence and conduction bands, and $E_{\mathrm{g}}$ is the band gap energy (see Table 2). The band gaps obtained were 3.105, 2.849, 2.786, and $2.713 \mathrm{eV}$ for pure $\mathrm{TiO}_{2}, \mathrm{~N}-\mathrm{TiO}_{2}, \mathrm{Al}-\mathrm{TiO}_{2}$, and $\mathrm{N}-\mathrm{Al}-\mathrm{TiO}_{2}$, respectively. The band gaps obtained by the theoretical calculation and those obtained by the experiments exhibited some differences; however, the difference was small, and the reduction tendency was the same. Thus, the $\mathrm{N}-\mathrm{Al}-\mathrm{TiO}_{2}$ catalyst can absorb the lower energy photons and generate more photogenerated electron-hole pairs, which can involve in the photocatalytic reaction and can improve the photocatalytic activities of the catalyst.

\subsection{Photocatalytic activities of the catalysts}

The photocatalytic activities of pure $\mathrm{TiO}_{2}, \mathrm{~N}-\mathrm{TiO}_{2}, \mathrm{Al}-\mathrm{TiO}_{2}$, and $\mathrm{N}-\mathrm{Al}-\mathrm{TiO}_{2}$ were studied by degrading the methyl orange (MO) solution under a simulated visible light irradiation. The results are shown in Fig. 6(a) and (b). According to the results shown in Fig. 6(a), it was obvious that the $\mathrm{N}-\mathrm{Al}$ codoped $\mathrm{TiO}_{2}$ catalyst exhibited the best effect on the degradation of the methyl orange solution, and the degradation rate was 5 times higher than that of pure $\mathrm{TiO}_{2}$. Fig. 6(b) shows the kinetics of the photocatalytic degradation of $\mathrm{MO}$ for pure $\mathrm{TiO}_{2}, \mathrm{~N}-\mathrm{TiO}_{2}, \mathrm{Al}-\mathrm{TiO}_{2}$, and $\mathrm{N}-\mathrm{Al}-\mathrm{TiO}_{2}$. The first-order rate (constant $k$ ) for $\mathrm{N}-\mathrm{Al}-\mathrm{TiO}_{2}$ was significantly higher than that for the other catalysts. It is clearly observed that $\mathrm{N}-\mathrm{Al}-\mathrm{TiO}_{2}$ exhibits the best photocatalytic performance. The photocatalytic results indicate that codoping of $\mathrm{N}$ and $\mathrm{Al}$ into $\mathrm{TiO}_{2}$ can effectively enhance the photocatalytic activities of $\mathrm{TiO}_{2}$.

\section{Conclusions}

In this study, the GGA + U method was used to calculate the electronic structures of pure $\mathrm{TiO}_{2}, \mathrm{~N}$ monodoped, $\mathrm{Al}$ monodoped, and $\mathrm{N}-\mathrm{Al}$ codoped $\mathrm{TiO}_{2}$. An appropriate Hubbard parameter $\left(U_{\text {eff }}\right)$ of $8.30 \mathrm{eV}$ was obtained and used to determine the band gap. Compared to $\mathrm{N}$ monodoped and $\mathrm{Al}$ monodoped, $\mathrm{N}-\mathrm{Al}$ codoped $\mathrm{TiO}_{2}$ could make the band gap narrower due to the emergence of the state of $\mathrm{N} 2 \mathrm{p}$ that led to an upward shift of the VBM and the emergence of the $\mathrm{Al} 3 \mathrm{p}$ state that gave rise to a downward shift of the CBM. Additionally, the electronic transition occurs from the valence band to the impurity level in 
$\mathrm{N}-\mathrm{Al}$ codoped $\mathrm{TiO}_{2}$, which is more beneficial to the absorption of visible light. Moreover, the experimental studies were performed to characterize the microstructures, elemental composition, and photocatalytic activities of the catalysts prepared by the sol-gel method. It is found that although $\mathrm{N}$ and $\mathrm{Al}$ atoms are successfully codoped into $\mathrm{TiO}_{2}$, the morphologies and the crystal forms of the catalysts remain unchanged. Importantly, N-Al codoped $\mathrm{TiO}_{2}$ has a higher crystallinity and a higher specific surface area, which are beneficial to improve the photocatalytic activity of the sample. Among all the prepared catalysts, $\mathrm{N}-\mathrm{Al}$ codoped $\mathrm{TiO}_{2}$ shows the best photocatalytic activity. We propose that the band gap narrowing can be the root cause for the enhancement of the photocatalytic activity due to the introduction of the of $\mathrm{N} 2 \mathrm{p}$ and $\mathrm{Al} 3 \mathrm{p}$ states into $\mathrm{N}-\mathrm{Al}$ codoped $\mathrm{TiO}_{2}$ under visible light.

\section{Conflicts of interest}

There are no conflicts to declare.

\section{Acknowledgements}

We would like to express our gratitude to all those who helped us during the writing of this paper. Special thanks to our friends who have put considerable time and effort into the comments on the draft. This work was supported by the Natural Science Foundation of Heilongjiang Province, China (No. B201422).

\section{Notes and references}

1 A. Mills and S. Le Hunte, J. Photochem. Photobiol., A, 1997, 108, 1-35.

2 X. An, Y. Wen, A. Almujil, D. Cheng, J. Li, X. Jia, J. Zou and Y. Ni, RSC Adv., 2016, 6, 89457-89466.

3 M. R. Hoffmann, S. T. Martin, W. Choi and D. W. Bahnemann, Chem. Rev., 1995, 95, 69-96.

4 L. Jing, Y. Cao, H. Cui, J. R. Durrant, J. Tang, D. Liu and H. Fu, Chem. Commun., 2012, 48, 10775-10777.

5 S. Y. Liu and Q. G. Feng, Adv. Mater. Res., 2011, 148, 12081211.

6 S. Steinberg, M. Valldor and G. Meyer, J. Solid State Chem., 2013, 206, 176-181.

7 W. Chen, T. Ye, H. Xu, T. Chen, N. Geng and X. Gao, RSC Adv., 2017, 7, 9880-9887.

8 J. Hu, Y. Cao, K. Wang and D. Jia, RSC Adv., 2017, 7, 1182711833.

9 Q. Meng, T. Wang, E. Liu, X. Ma, Q. Ge and J. Gong, Phys. Chem. Chem. Phys., 2013, 15, 9549-9561.

10 S. Liu, G. Liu and Q. Feng, J. Porous Mater., 2010, 17, 197206.

11 L. Schlur, S. Begin-Colin, P. Gilliot, M. Gallart, G. Carré, S. Zafeiratos, N. Keller, V. Keller, P. André and J. M. Greneche, Mater. Sci. Eng., C, 2014, 38, 11-19.

12 Q. P. Liu, H. J. Huang, Y. Zhou, Y. D. Duan, Q. W. Sun and Y. Lin, Acta Phys.-Chim. Sin., 2012, 28, 591-595.

13 Y. Fang, D. Cheng and W. Wu, Comput. Mater. Sci., 2014, 85, 264-268.
14 S. Y. Yang, L. F. Yao and H. Chen, Adv. Mater. Res., 2014, 963, 529-533.

15 G. Wu, S. Zheng, P. Wu, J. Su and L. Liu, Solid State Commun., 2013, 163, 7-10.

16 C. Stampfl and C. Van de Walle, Phys. Rev. B: Condens. Matter Mater. Phys., 1999, 59, 5521.

17 S. Biermann, F. Aryasetiawan and A. Georges, Phys. Rev. Lett., 2003, 90, 086402.

18 K. Terakura, T. Oguchi, A. Williams and J. Kübler, Phys. Rev. B: Condens. Matter Mater. Phys., 1984, 30, 4734.

19 S. Dudarev, G. Botton, S. Savrasov, C. Humphreys and A. Sutton, Phys. Rev. B: Condens. Matter Mater. Phys., 1998, $57,1505$.

20 G. Liu, L. C. Yin, J. Wang, P. Niu, C. Zhen, Y. Xie and H. M. Cheng, Energy Environ. Sci., 2012, 5, 9603-9610.

21 W. J. Yin, H. Tang, S. H. Wei, M. M. Al-Jassim, J. Turner and Y. Yan, Phys. Rev. B: Condens. Matter Mater. Phys., 2010, 82, 045106.

22 W. J. Yin, S. H. Wei, M. M. Al-Jassim and Y. Yan, Phys. Rev. Lett., 2011, 106, 066801.

23 B. Yuzer, M. Guida, F. Ciner, B. Aktan, M. I. Aydin, S. Meric and H. Selcuk, Desalin. Water Treat., 2016, 57, 4966-4973.

24 V. Caratto, F. Locardi, S. Alberti, S. Villa, E. Sanguineti, A. Martinelli, T. Balbi, L. Canesi and M. Ferretti, J. Sol-Gel Sci. Technol., 2016, 80, 152-159.

25 C. B. Marien, C. Marchal, A. Koch, D. Robert and P. Drogui, Environ. Sci. Pollut. Res., 2017, 24, 12582-12588.

26 X. Li, H. Gao and G. Liu, Comput. Theor. Chem., 2013, 1025, 30-34.

27 J. K. Burdett, T. Hughbanks, G. J. Miller, J. W. Richardson Jr and J. V. Smith, J. Am. Chem. Soc., 1987, 109, 3639-3646.

28 H. C. Wu, Y. S. Lin and S. W. Lin, Int. J. Photoenergy, 2013, 2013, 1-7.

29 A. A. Murashkina, P. D. Murzin, A. V. Rudakova, V. K. Ryabchuk, A. V. Emeline and D. W. Bahnemann, J. Phys. Chem. C, 2015, 119, 24695-24703.

30 X. J. Zhang, G. F. Zhang, H. X. Jin, L. D. Zhu and Q. J. Liu, Acta Phys. Sin., 2013, 62, 017102.

31 Z. Y. Zhang, P. D. Han, C. L. Zhang, X. Zhang, X. L. Sun and Y. P. Li, Acta Phys.-Chim. Sin., 2012, 28, 324-330.

32 T. J. Giese and D. M. York, J. Chem. Phys., 2010, 133, 244107. 33 Y. Gai, J. Li, S. S. Li, J. B. Xia and S. H. Wei, Phys. Rev. Lett., 2009, 102, 036402.

34 R. Long and N. J. English, Chem. Mater., 2010, 22, 1616-1623.

35 H. Pan, Y. W. Zhang, V. B. Shenoy and H. Gao, J. Phys. Chem. $C, 2011,115,12224-12231$.

36 E. Escamilla-Roa, V. Timon and A. Hernandez-Laguna, Comput. Theor. Chem., 2012, 981, 59-67.

37 C. Lee and C. M. Aikens, Comput. Theor. Chem., 2013, 1013, 32-45.

38 J. Zhang, L. Qian, W. Fu, J. H. Xi and Z. G. Ji, J. Am. Ceram. Soc., 2014, 97, 2615-2622.

39 J. Zhang, J. Xi and Z. Ji, J. Mater. Chem., 2012, 22, 1770017708.

40 B. Jiang, X. L. Yang, X. Li, D. Q. Zhang, Z. Jian and G. S. Li, J. Sol-Gel Sci. Technol., 2013, 66, 504-511. 